\title{
Inconsistencies of the Consistency test
}

\author{
Mary Moroney*
}

\begin{abstract}
The Consistency test from Dayal 2004 —inspired by Löbner's (1985) logical property of Consistency - has been used to distinguish between demonstratives and definite determiners in a language, particularly in a type-shifting analysis of bare nouns following Chierchia 1998 and Dayal 2004. This paper looks at three classifier languages, Nuosu Yi (Jiang 2018), Thai (Jenks 2015), and Shan (Moroney 2018) and examines the use of the Consistency test in the study of N/DP syntax and semantics. While the Consistency test can identify demonstratives from their ability to shift reference using deixis, it cannot identify when a nominal expression 'counts' as a definite determiner.
\end{abstract}

Keywords. semantics; bare nouns; Consistency test; Law of Contradiction; classifier languages; type-shifting

1. Background. The Consistency test originally derives from Löbner's (1985) logical property of Consistency, which simply says that a one-place predicate and its negation cannot be evaluated true for a single individual term.

(1) Consistency (Löbner 1985): If $P$ is true for an individual term $t$, then $\neg P$ cannot be true for $t$

Dayal (2004) adopted this property as a diagnostic to distinguish between demonstratives and 'true definites' (417). As shown (2) and (3), the English demonstrative and determiner clearly display a distinct pattern in this construction, where a predicate is followed by its negation ('is sleeping' and 'is not sleeping') while the same nominal expression ('the child') in (2) and ('that child') in (3) ${ }^{1}$ appears with both the positive and negative predicate.

(2) \#The child is sleeping but the child is not sleeping.

(3) That child is sleeping but that child is not sleeping.

Example (2) is infelicitous because 'the child' in both clauses refers to the same individual, violating Consistency. Example (3), in contrast is not infelicitous because the deictic nature of the demonstrative allows 'that child' in the first clause to refer to a different individual than 'that child' in the second clause.

Since the English determiner 'the' and demonstrative 'that' pattern differently in this type of construction, people have used this Consistency test to say whether a word in a language is or isn't a 'true determiner'. The problem with using this test in this way is that it assumes that an expression having the properties of a demonstrative cannot also have the properties of

*Thanks to Nan San Hwam, Mai Hong, and Sai Loen Kham who provided the Shan data and to Sireemas Maspong who helped with the Thai data. Thanks also to everyone who provided feedback on this presentation, especially the audience at the LSA 2019, Ekarina Winarto, and Carol-Rose Little. Any errors are my own. Authors: Mary Moroney, Cornell University (mrm366@cornell.edu)

${ }^{1}$ An LSA audience member pointed out that when we say (3), we actually pronounce the two tokens that child differently using prosodic focus. 
a determiner (and presumably vice versa). In particular, this test has been employed in a typeshifting analysis of bare nouns. What this paper will show is that the Consistency test relies on too narrow a notion of definiteness and thus fails to predict the range of data found in bare noun languages cross-linguistically.

1.1 A TYPE-SHIFTING ANALYSIS OF BARE NOUNS. In some languages, bare nouns can have different interpretations in different environments, as demonstrated for Shan, a Southwestern Tai language: ${ }^{2}$

\section{(4) ShAN BARE NOUN INTERPRETATIONS}

a. măa hàw jù.

dog bark IMPF

'Dogs are barking.'

'The $\operatorname{dog}(\mathrm{s})$ is/are barking.'

existential: $\quad \exists$

definite: $\iota$

b. măa hàw.

dog bark

'Dogs bark.'

c. măa motwáaj hăaj kwàa jâw.

generic: Gen

dog disappear disappear go PRF

'Dogs are extinct.'

kind:

d. mán pěn măa.

3 be dog

'S/he is a dog.'

predicate:

In (4-a), both an existential and definite interpretation are available. In (4-b), without the aspect marker, an additional generic interpretation is available. (4-c) shows that a bare noun is also compatible with a kind interpretation, and (4-d) shows that a bare noun can appear in predicate position.

A neo-Carlsonian type-shifting analysis, introduced by Chierchia (1998) and Dayal (2004), has been proposed for bare nouns for a variety of languages, including Hindi (Dayal 2004), Mandarin (Yang 2001; Jenks 2018), Nuosu Yi (Jiang 2018), Teotitlán del Valle Zapotec (Deal \& Nee 2017), Thai (Jenks 2015), and Indonesian (Little \& Winarto 2018). The basic idea is that, instead of having determiners to change a type $\langle e, t\rangle$ noun into type $e$, type-shifting operators apply to fix type mis-matches. Below are Dayal's (2004) proposed type-shifting operators:

\footnotetext{
${ }^{2}$ Data for this paper comes from my fieldwork with the Shan language in Chiang Mai, Thailand from January 2018 to present, working with a speaker from Keng Tawng City in Shan State, Myanmar, who has lived in Thailand for over 10 years. Data was collected using a variety of elicitation methods: story translation, stories based on storyboards, felicity judgments on grammatical sentences in specific contexts. ${ }^{3}$

Glossing conventions: 1: first person, 3: third person, CLF: classifier, INDEF: indefinite, IMPF: imperfect, NEG: negation, PRF: perfect SG: singular
} 
(5) TYPE SHIFTING OPERATORS (Dayal 2004: (77a)): $\langle e, t\rangle \rightarrow e /\langle\langle e, t\rangle, t\rangle$
a. $\quad \cap: \lambda P \lambda s \iota x\left[P_{s}(x)\right]$
b. $\iota: \lambda P \iota x\left[P_{s}(x)\right]$
c. $\quad \exists: \lambda P \lambda Q \exists x\left[P_{s}(x) \& Q(x)\right]$

Identifying the determiners of a language is important for the type-shifting analysis of definiteness because the available determiners in a language are said to constrain what typeshifting is available. The Blocking principle was introduced to constrain what type shifting operations are available in a language: ${ }^{4}$

(6) Blocking PRinciple (Dayal 2004: (77c)): For any type shifting operation $\pi$ and any $X: * \pi(X)$ if there is a determiner $\mathrm{D}$ such that for any set $X$ in its domain, $D(X)=$ $\pi(X)$

Essentially: "Don't do covertly what you can do overtly!" (Jenks 2018: (23))

Dayal (2004) summarizes the motivation for the Blocking Principle saying the following:

The intuition behind this principle is that for considerations of economy lexical items must be exploited to the fullest by a language before covert type-shift operations are used. (Dayal 2004: 417)

Dayal (2004) used the Consistency test to claim that the Hindi demonstrative is not a true definite determiner and thus does not block $\iota$ type shifting in Hindi. ${ }^{5}$

The goal of this paper is to demonstrate that this test can identify demonstratives, but it is problematic to use it to identify what counts as a determiner for the Blocking principle. In $\S 2$, definiteness will be split into weak and strong definiteness in order to delve more deeply into the difference between the meanings of the determiner and demonstrative. $\S 3$ will discuss the previous uses of the Consistency Test and why those uses are problematic. In $\S 4$, we will see what the Consistency Test does tell us. $\S 5$ contains the discussion, and $\S 6$ concludes.

2. Types of definiteness. Schwarz (2009) proposed that there are two types of definiteness expressed by German:

i weak, contracted form (e.g., vom ('by the')), expressing uniqueness

ii strong, non-contracted form (e.g., von dem ('by the')), expressing anaphoricity/familiarity

In (7) is an example of weak definiteness, expressing uniqueness. The glass cabinet is unique in the context, so the weak, contracted form im must be used instead of the strong, non-contracted form in dem.

\footnotetext{
${ }^{4}$ Problems with the Blocking Principle have been identified by Little \& Winarto (2018) stemming from the appearance of a definite determiner in Indonesian that is optional in definite environments.

${ }^{5}$ Gillon (2015) also uses this test to examine the syntax and semantics of bare nouns, but that use is beyond the scope of this paper.
} 
Das Buch, das du suchst, steht im / \#in dem Glasschrank. the book that you look-for stands in-the weak $_{\text {in }} /$ in thtrong $_{\text {slass-cabinet }}$ 'The book that you are looking for is in the glass-cabinet.'

In (8), we have an example of strong definiteness, expressing anaphoricity. Here, we have einen Politiker 'a politician' introduced in the first sentence. The second sentence refers back to that politician using the strong from von dem instead of the weak form vom.

German: ANAPHORIC DEFINITE (Schwarz (2009): (23))

Hans hat einen Schriftsteller und einen Politiker interviewt. Er hat \#vom / Hans has a writer and a politician interviewed He has from-the weak $_{\text {/ }}$ von dem Politiker keine interessanten Antworten bekommen.

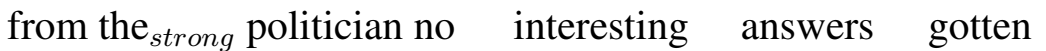

'Hans interviewed a writer and a politician. He didn't get any interesting answers from the politician.'

In English, the is used in both unique and anaphoric definite environments, as shown in (9) and (10). (9) shows that the English demonstrative that cannot be used in unqiue definite environments. However, that is able to be used in anaphoric definite environments, as in (10), suggesting that the English demonstrative is also compatible with this type of definiteness. As (11) shows, that is used with deixis but the cannot.

(9) ENGLish: UNIQUE DEFINITE

The/\#That sun is shining.

\section{ENGLISH: ANAPHORIC DEFINITE}

Hans interviewed a writer and a politician. He didn't get any interesting answers from the/that politician.

ENGLISH: DEIXIC DEFINITE

\#The/That child is sleeping. (Context: pointing at a child)

Table 1 summarizes the compatibility of these two English definiteness markers with different definite environments. Both can be used to express anaphoric definiteness, but they are otherwise used in different contexts.

\begin{tabular}{lccc}
\hline & Unique & Anaphoric & Deictic \\
\hline the & $\checkmark$ & $\checkmark$ & $\#$ \\
that & $\#$ & $\checkmark$ & $\checkmark$ \\
\hline
\end{tabular}

Table 1: English definiteness marking

It has also been claimed that Thai (Jenks 2015) and Mandarin (Jenks 2018) have these two types of definiteness, but uniqueness is expressed by a bare noun and anaphoricity is conveyed by a demonstrative expression. Jenks (2018) proposed the typology of definiteness marking shown in Table 2.

Importantly, the marked anaphoric cases include both (i) the demonstrative expresses anaphoric 


\begin{tabular}{lcccc}
\hline & Bipartite & Marked anaphoric & Generally marked & Marked unique \\
\hline Unique $(\iota)$ & Def $_{\text {weak }}$ & $\emptyset$ & Def & Def $_{\text {weak }}$ \\
Anaphoric $\left(\iota^{x}\right)$ & Def $_{\text {strong }}$ & Def & Def & $\emptyset$ \\
Languages & German, & Mandarin, & Cantonese, & \\
& Lakhota & Akan, Wu & English & (unattested) \\
\hline
\end{tabular}

Table 2: Typology of definiteness marking (Jenks 2018: 530)

definiteness in Mandarin (Jenks 2018), and (ii) a definite expression separate from the demonstrative expresses anaphoric definiteness in Akan (Arkoh \& Matthewson 2013) and Wu (Simpson 2017). According to the Consistency test, the Mandarin demonstrative does not have the status of a determiner even thought it expresses anaphoric definiteness in the language. For the remainder of this paper, I will be focusing on how the examined set of languages expresses anaphoric definiteness.

3. Previous use: Three case studies. This section examines the use of the consistency test in three classifier languages that do not mark plurality: Shan (Moroney 2018), Thai (Jenks 2015), and Nuosu Yi (Jiang 2018). These three languages will demonstrate that the Consistency test does not predict the obligatoriness of determiners, particularly in anaphoric environments.

It is clear that the Shan demonstrative behaves like a demonstrative in terms of the Consistency test, shown in (12). However, it is optionally available to express anaphoric definiteness, as shown in (13) and (14).

SHAN: CONSISTENCY TEST (Moroney 2018: (24))

kók hòj nâj pěn ši khăaw. kók hòj nâj pěn sí lăm. cup CLF.ROUND this be color white cup CLF.ROUND this be color black 'This cup is white. This cup is black.'

(13) SHAN: ANAPHORA (Moroney 2018: (13))

phu-tsáaj kô nưg kwàa ti hâan khăaj măa tàa sû măa ?òn person-man CLF.PERSON one go at store sell dog for buy dog small tǒ nự păn luk jín mán-tsáaj... phu-tsáaj (k̂̀ nân) khún CLF.ANIMAL one give child girl 3-man person-man CLF.PERSON that back tòp waa, respond that

'A man went to a dog store to buy a puppy for his daughter... The/that man replied,'

(14) SHAN: ANAPHORA

phu-tsáaj kô nưg le phu-jíy kô num nay jù náj person-man CLF.PERSON one and person-woman CLF.PERSON one sit IMPF in hoj. phu-jín (k̂̀ nân) haajlì nàa. room person-woman CLF.PERSON that pretty very 'A man and a woman are sitting in a room. The/that woman is very pretty.'

The Shan pattern is largely consistent with what is predicted by Dayal's (2004) analysis. 
The Thai demonstrative patterns like a demonstrative in the Consistency test (15), but it is also obligatory when expressing anaphoric definiteness, shown in in (16). The obligatoriness of the demonstrative in Thai anaphoric definite cases, suggests that the Blocking Principle is in effect, yet according to the Consistency test, the demonstrative should not be considered a definite determiner. Thus, Thai poses a potential problem for using this test to predict the obligatoriness of certain nominal expressions in definite environments.

THAi: CONSISTENCY TEST (Jenks 2015: (3))

dèk khon nán noon yùu tèc dèk khon nán mâi.dâi noon yùu. child CLF that sleep IMPF but child CLF that NEG sleep IMPF 'That child is sleeping but that child is not sleeping.'

(16) THAI: ANAPHORA (Jenks 2015: (17))

mî̀awaan phǒm cəə kàp nákrian khon nị. (nákrian) \#(khon nán) chalàat yesterday 1ST meet with student CLF INDEF student CLF that clever mâak.

very

'Yesterday I met a student. That student was very clever.'

Jiang (2018) uses the Consistency test to identify the Nuosu Yi definite determiner, su in (17).

NuOsu Yi: CONSISTENCY TEST (Jiang 2018: (8b))

\#nga si-hni ma su hxie-vur, si-hni ma su hxie-ap-vu

I girl CLF Su like girl CLF Su like-not

'\#I like the girl but don't like the girl.'

However, the consistency test cannot account for its optionality in definite constructions, as in (18). Here, again, we see that the Consistency test is not predicting the observed patterns.

NuOsu Yi: ANAPHORA WITH DEFINITE (Jiang 2018: (9a,b))

si-hni ma sini sse-vo ma i-go nyi, si-hni (ma su) jjy nra.

girl CLF and boy CLF room sit girl CLF Su very beau.

'A girl and a boy are sitting in the room, the girl is very pretty.'

The results of the Consistency test do not correlate with the obligatoriness of the demonstrative/definite in anaphoric definite contexts in Nuosu Yi and Thai. This is summarized in Table 3.

\begin{tabular}{l|c|c|c} 
& Shan dem. & Thai dem. & $\begin{array}{c}\text { Nuosu Yi } \\
\text { det. }\end{array}$ \\
\hline \hline Consistency test & $\checkmark$ & $\checkmark$ & $\#$ \\
\hline $\begin{array}{l}\text { Use in anaphoric } \\
\text { definite context }\end{array}$ & optional & obligatory & optional
\end{tabular}

Table 3: Summary of three case studies

4. What the Consistency test tells us. It isn't that the Consistency test doesn't tell us anything. What it tells us is simply whether a nominal expression has a fixed reference in a par- 
ticular linguistic context. We can still use this test to probe whether a nominal expression can shift reference in a particular context. For example, when a demonstrative is used anaphorically, the Consistency test results in a contradiction, as in (19). The Thai demonstrative produces the same contradictory reading when it is used anaphorically, as in (20). This shows us that demonstrative-noun phrases have fixed reference when used anaphorically.

ENGLish: CONSISTENCY TEST WITH ANAPHORA

There is a child in the next room. \#That child is sleeping but that child is not sleeping.

THAi: CONSISTENCY TEST WITH ANAPHORA

mii dèk khon nìn yùu nay hôon thàt pay. \#dèk khon nán noon yùu tèc dèk have child CLF one LOC in room next PRT child CLF that sleep IMPF but child khon nán mâi.dâi noon yùu.

CLF that NEG sleep IMPF

'There is a child in the next room. \#That child is sleeping but that child is not sleeping.'

Using deixis with the second 'that' can make these examples felicitous. What this shows is that deixis the way to shift reference of a demonstrative expression. The anaphoric use of the demonstrative does not by itself allow reference shifting.

5. Discussion. The definiteness marking patterns discussed in the previous section can be summarized in the format of Jenks 2018 as in Table 4. The Thai case mirrors the Mandarin case, being marked in anaphoric definite cases. In Shan, definiteness is generally unmarked, though anaphoric definiteness can be marked with a demonstrative. ${ }^{6}$ Then there is what seems to be a fully optionally marked case, where both unique and anaphoric definiteness can be expressed using a bare noun or a noun modified by a determiner.

\begin{tabular}{lccc}
\hline & Marked anaphoric & Generally unmarked & Optionally marked \\
\hline Unique $(\iota)$ & $\emptyset$ & $\emptyset$ & $\emptyset /$ Def \\
Anaphoric $\left(\iota^{x}\right)$ & Def $_{d e m}$ & $\emptyset /$ Def $_{d e m}$ & $\emptyset /$ Def \\
Languages & Thai & Shan & Nuosu Yi, Indonesian \\
\hline
\end{tabular}

Table 4: Typology of definiteness marking

5.1 ANALYSis OF THAI, JENKS 2015, 2018. Jenks's (2015) has an analysis for why the Thai bare noun cannot be used in anaphoric environments, but he has a more recent analysis in Jenks's (2018) for Mandarin. He claims that "basically identical facts hold in Thai" (Jenks 2018: 531), so I will discuss the Jenks 2018 analysis as if it applies to Thai.

The analysis is as follows:

1. Unique and anaphoric definiteness are expressed separately in Thai, following Schwarz's (2009) analysis of German definite articles.

\footnotetext{
${ }^{6}$ From the discussion about Hindi, I think Jenks (2018) would say that Shan should be classified as 'generally marked' with a null definite determiner. Here I give it a separate category and also highlight the optional demonstrative use in the anaphoric case.
} 
2. Unique definiteness is expressed using bare nouns that type-shift via $\iota$.

3. Anaphoric definiteness requires an extra semantic argument that can be filled by an index.

4. $\iota$ cannot be used in anaphoric cases because "there is a default preference in Mandarin and German for explicitly representing indices whenever possible" (Jenks 2018: 524). This is a form of Maximize Presupposition (Heim 1991).

Given that there are languages where bare nouns can express anaphoric definiteness, like Shan, as in (13), or in Nuosu Yi, as in (18), how can we predict the case of Thai? If there were a cross-linguistic preference for overtly expressing indices, why are there so many languages that can express anaphoric definiteness with a bare noun. If there is no such crosslinguistic preference, is there a way to predict which languages do have such a preference for overtly marking anaphoric definiteness?

This type of analysis works better for German, where there is competition between two overt definite articles, or for a language like Akan or $\mathrm{Wu}$, where an overt anaphoric definite article-distinct from the demonstrative-would 'block' anaphoric definite type shifting. If there is competition between two determiners or between being unmarked or marked, it would make sense for the anaphoric determiner to be obligatory to express anaphoric definiteness. Do we, then, want to say that the demonstrative in Thai functions as an anaphoric definite determiner?

In Jenks 2018, there is no mention of the consistency test, but Jenks (2015) does use it to show that demonstratives are 'not translational equivalents of definite articles' (105). In the analysis summarized above, Jenks (2018) does not seem to want to say that the Thai demonstrative is functioning as the anaphoric definite determiner in the language, and thus blocking some anaphoric type-shifting. In fact, he suggests that type-shifting cannot introduce an index (Jenks 2018: 503).

5.2 Analysis of NuOsu Yi, Jiang 2018. For Nuosu Yi, the explanation that Jiang (2018) gives for why $s u$ is optional in definite contexts is by saying that the definite article is applying at a higher level than the bare noun. When the definite article or a demonstrative combine with a noun, a classifier is required.

NuOSU Yi: DEFINITE (Jiang 2018: (40b))

tsho $*(\mathrm{ma})$ su

man CLF the

'the man'

The argument is as follows:

1. $s u$ is a determiner, following the Consistency test results.

2. The bare noun is a kind and can be type shifted into an entity, using one of the paths discussed by Trinh (2011), Dayal (2011), or Jiang (2012).

3. A classifier shifts the noun from a kind to a property of type $\langle e, t\rangle$, which can combine with the determiner $s u$. 
4. Blocking does not take place because the determiner does not apply to bare nouns.

5. Thus both $\iota$ type-shifting and the definite determiner are available in the language.

This can explain the case of Nuosu Yi. However, if we were to say that the Thai demonstrative is functioning as an anaphoric definite article, that would be problematic for this explanation because (i) the Thai demonstrative is obligatory in anaphoric definite contexts; and (ii) just like in Nuosu Yi, the classifier must appear with the demonstrative, shown in (22).

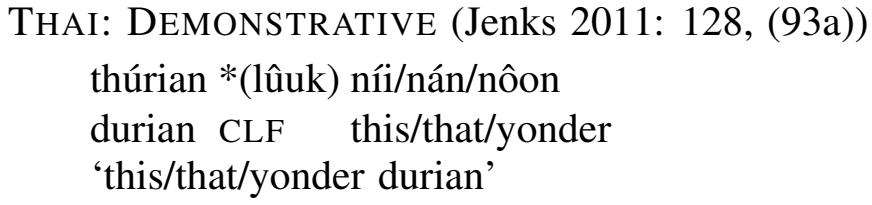

We would expect that if Jiang's (2018) explanation were applicable to Thai, the demonstrative should be optional in definite anaphoric contexts in Thai.

5.3 The status of THE CONSISTENCY TEST. This leaves us with a few options for interpreting the role of the Consistency test as it relates to the Blocking principle:

\section{Option 1: The Consistency test identifies definite determiners}

Nuosu Yi determiner optionality in anaphoric contexts can be explained along the lines of Jiang (2018). However, the obligatoriness of the Thai demonstrative in anaphoric contexts would be difficult to explain in a way that is consistent with the Nuosu Yi and Shan cases. If the Thai demonstrative is an anaphoric definite determiner, the Consistency test cannot tell us that. If the Thai demonstrative is a demonstrative, we have to rely on an apparently languagespecific preference for overt expression of indices to explain the pattern of data.

\section{Option 2: The Consistency test only demonstrates fixed reference of a nominal expression}

We lose a means of identifying definite determiners and consequently lose a means of constraining type-shifting. This is not ideal, but perhaps we can find a better way to constrain type-shifting.

6. Conclusion. The Consistency test provides information about the reference produced by a particular nominal expression in a particular context. However, it fails to predict the obligatoriness of determiner/demonstrative elements in definite contexts in Nuosu Yi and Thai. Therefore, I would suggest that it should not be used as evidence that a particular nominal expression is or is not functioning as a definite determiner for the purposes of the Blocking Principle that constrains type-shifting.

We might need to take another look at the validity of the Blocking Principle based on these cases and based on the case of Indonesian discussed by Little \& Winarto (2018), where the definite determiner is optional and cannot rely on the classifier-based explanation for $\mathrm{Nu}-$ osu Yi. An analysis that predicts that a determiner must be obligatory or missing altogether might be too strong. Instead we might take a closer look at the contexts that prefer or require the use of a demonstrative when we might expect a an anaphoric bare noun or determiner to be used. 


\section{References}

Arkoh, Ruby \& Lisa Matthewson. 2013. A familiar definite article in Akan. Lingua 123. 1-30.

Chierchia, Gennaro. 1998. Reference to kinds across language. Natural language semantics 6(4). 339-405.

Dayal, Veneeta. 2004. Number marking and (in) definiteness in kind terms. Linguistics and philosophy 27(4). 393-450.

Dayal, Veneeta. 2011. Bare noun phrases. In Claudia Maienborn, Klaus von Heusinger \& Paul Portner (eds.), Semantics: An international handbook of natural language meaning, vol. 2, Walter de Gruyter.

Deal, Amy Rose \& Julia Nee. 2017. Bare nouns, number, and definiteness in Teotitlán del Valle Zapotec. Proceedings of Sinn und Bedeutung 21.317-334. https:// semanticsarchive.net/Archive/DRjNjViN/index.html.

Gillon, Carrie. 2015. Investigating D in languages with and without articles. In M. Ryan Bochnak \& Lisa Matthewson (eds.), Methodologies in semantic fieldwork, chap. 7, 175203. Oxford: Oxford University Press.

Heim, Irene. 1991. Artikel und definitheit. Semantik: Ein internationales Handbuch der Zeitgenössischen forschung. 487-535.

Jenks, Peter. 2015. Two kinds of definites in numeral classifier languages. In Sarah D’Antonio, Mary Moroney \& Carol-Rose Little (eds.), Semantics and linguistic theory (SALT), vol. 25, 103-124. LSA and CLC Publications. https://doi.org/10.3765/salt.v25i0.3057.

Jenks, Peter. 2018. Articulated definiteness without articles. Linguistic Inquiry 49(3). 501-536.

Jenks, Peter Spiros Eric. 2011. The hidden structure of Thai noun phrases: Harvard University Cambridge, Massachusetts dissertation.

Jiang, Li. 2012. Nominal arguments and language variation: Harvard University Cambridge, Massachusetts dissertation.

Jiang, Li Julie. 2018. Definiteness in Nuosu Yi and the theory of argument formation. Linguistics and Philosophy 41(1). 1-39.

Little, Carol-Rose \& Ekarina Winarto. 2018. Classifiers and the definite article in Indonesian. Presented at the 49th meeting of the North East Linguistics Society (NELS) .

Löbner, Sebastian. 1985. Definites. Journal of semantics 4(4). 279-326.

Moroney, Mary. 2018. Definiteness in Shan. Proceedings of the ESSLLI 2018 Student Session 174-186. http://esslli2018.folli.info/wp-content/uploads/Proceedings-of-theESSLLI-2018-Student-Session.pdf.

Schwarz, Florian. 2009. Two types of definites in natural language. University of Massachusetts Amherst.

Simpson, Andrew. 2017. Bare classifier/noun alternations in the Jinyun (Wu) variety of Chinese and the encoding of definiteness. Linguistics 55(2). 305-331.

Trinh, Tue. 2011. Nominal reference in two classifier languages. Sinn und Bedeutung 15629.

Yang, Rong. 2001. Common nouns, classifiers, and quantification in Chinese: Rutgers University New Brunswick dissertation. 